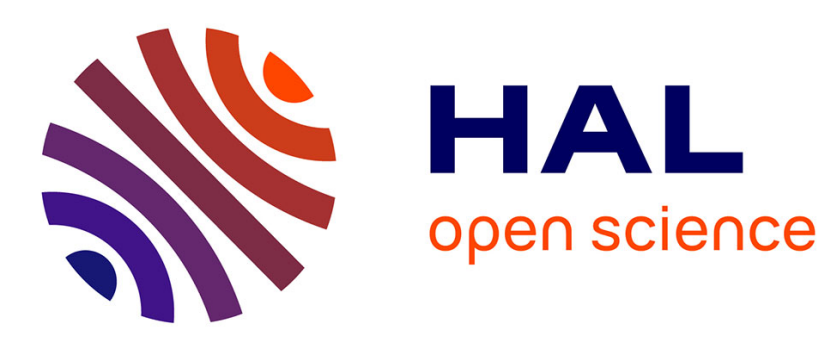

\title{
The effect of mean stress and stress biaxiality in high-cycle fatigue
}

\author{
Imade Koutiri, Daniel Bellett, F Morel
}

\section{To cite this version:}

Imade Koutiri, Daniel Bellett, F Morel. The effect of mean stress and stress biaxiality in high-cycle fatigue. Fatigue and Fracture of Engineering Materials and Structures, 2017, 10.1111/ffe.12699 . hal-01665347

\section{HAL Id: hal-01665347 \\ https://hal.science/hal-01665347}

Submitted on 15 Dec 2017

HAL is a multi-disciplinary open access archive for the deposit and dissemination of scientific research documents, whether they are published or not. The documents may come from teaching and research institutions in France or abroad, or from public or private research centers.
L'archive ouverte pluridisciplinaire HAL, est destinée au dépôt et à la diffusion de documents scientifiques de niveau recherche, publiés ou non, émanant des établissements d'enseignement et de recherche français ou étrangers, des laboratoires publics ou privés. 


\title{
The effect of mean stress and stress biaxiality in high-cycle fatigue
}

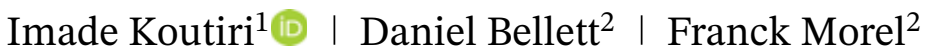

${ }^{1}$ PIMM, ENSAM, CNRS, CNAM, 151 Bd de l'Hopital, 75013 Paris, France

${ }^{2}$ LAMPA, ENSAM, 2 Bd du Ronceray, 49035 Angers Cedex 1, France

\section{Correspondence}

Imade Koutiri, PIMM, ENSAM, CNRS, CNAM, 151 Bd de l'Hopital, 75013 Paris, France.

Email: imade.koutiri@ensam.eu

\begin{abstract}
This article presents a review of selected multiaxial high-cycle fatigue criteria with an emphasis on their ability to take into account the mean stress effect and the effect of a biaxial stress state. It is shown that the predictions of the various criteria are very different for the case of biaxial tensile loads. This is in contrast to the case of combined tension-torsion loads, where the predictions are very similar. The second part of the article investigates which mechanical parameter (eg, the hydrostatic stress or the normal stress) is the most appropriate to take into account these cyclic stress states.
\end{abstract}

\section{KEYWORDS}

biaxial stress, high-cycle fatigue, hydrostatic stress, mean stress effect, multiaxial criteria, normal stress

\section{1 | INTRODUCTION}

High-cycle fatigue (HCF) of engineering materials is a phenomenon that results in the failure of real components and structures in service. Its progressive and hidden character that can lead to sudden and catastrophic failure makes it essential to correctly predict the fatigue life of a structure.

The factors influencing the fatigue behaviour of a material or a structure are numerous (eg, loading mode, microstructural heterogeneities, residual stresses, temperature, and environment), and this makes fatigue a complex phenomenon to study. Much research has been undertaken to better understand the influence of these factors, and one of the principal aims of this work is to investigate the "mean stress effect" and to asses the ability of certain fatigue criteria to correctly predict its influence.

For the case of uniaxial cyclic stresses, that is, either tensile or bending loading modes, many experimental results for metallic materials show an adverse effect of a positive mean stress. Figure 1 shows a large number of experimental uniaxial fatigue data taken from the literature ${ }^{1-10}$ represented in the form of a normalised Haigh diagram. Figure 1 also shows the well-known empirical uniaxial criteria proposed by Goodman ${ }^{11}$ and Gerber ${ }^{12}$ to account for the mean stress.

For the case of torsional loads, Davoli et al ${ }^{13}$ demonstrated that the mean stress effect is less pronounced than for the uniaxial case. By considering data from the literature and their own tests conducted on a high-strength

Nomenclature: $R$, Load ratio; $k$, Biaxiality ratio; $\sigma$, Stress at the mesoscopic scale; $\tau_{a}$, Shear stress amplitude at mesoscopic scale; $s_{-1}$, Uniaxial fatigue strength for a load ratio of $R=-1 ; s_{0}$, Uniaxial fatigue strength for a load ratio of $R=0$; $t_{-1}$, Torsional fatigue strength for a load ratio of $R=-1 ; t_{0}$, Torsional fatigue strength for a load ratio of $R=0 ; f_{\text {rot-1 }}$, Rotating bending fatigue strength for a load ratio of $R=-1 ; \Sigma$, Stress at the macroscopic scale or engineering scale; $\Sigma_{U T S}$, The ultimate tensile strength; $\Sigma_{Y}$, The yield strength; $\Sigma_{N}$, Normal stress; $\Sigma_{N, a}$, Amplitude of the normal stress; $\Sigma_{N, m}$, Normal mean stress; $\Sigma_{H}$, Hydrostatic stress; $\Sigma_{H, a}$, Amplitude of the hydrostatic stress; $\Sigma_{H, m}$, Mean hydrostatic stress; $\Sigma_{i j}^{e}$, Elastic stress tensor; $\Sigma_{i j}^{p}$, Plastic stress tensor; $\varepsilon_{i j}^{e}$, Elastic strain tensor; $\varepsilon_{i j}^{p}$, Plastic strain tensor; $v$, Poisson coefficient; $E$, Young modulus; $W$, Strain energy density; $T_{a}$, Macroscopic shear amplitude stress; $T_{m}$, Macroscopic shear mean stress; $T_{0}$, Weibull distribution scale factor; $m$, Weibull exponent; $\gamma_{\text {cum }}$, Accumulated plastic strain; 


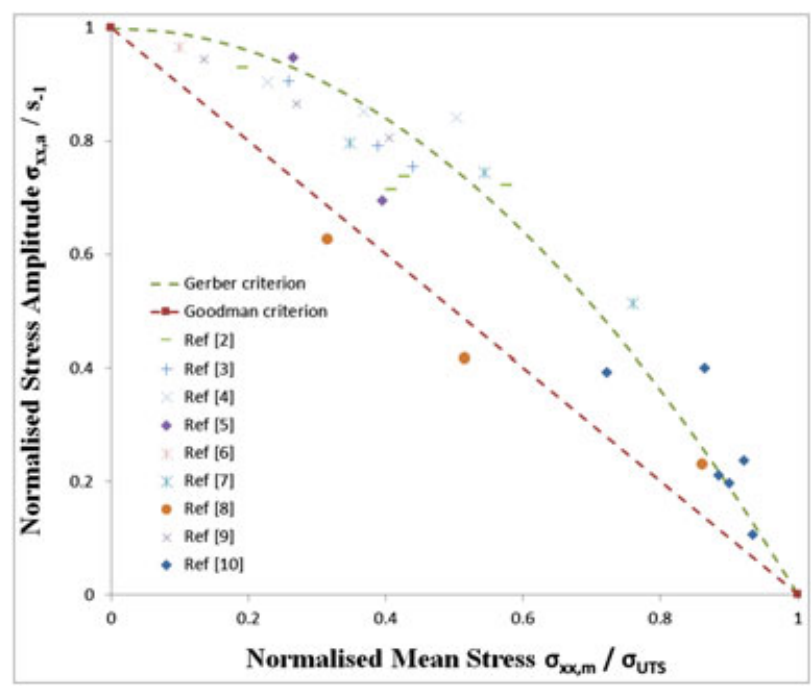

FIGURE 1 Normalised Haigh diagram showing the Goodman and Gerber criteria [Colour figure can be viewed at wileyonlinelibrary.com]

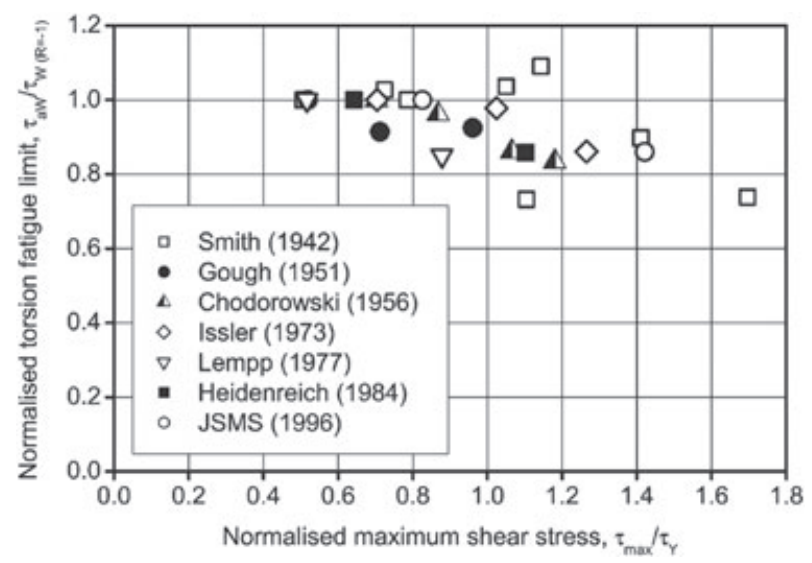

FIGURE 2 Effect of mean torsional stress on the torsional fatigue strength $^{13}$

steel, they showed that the torsional fatigue strength is relatively independent of the torsional mean stress, as long as the material rests globally elastic (see Figure 2).

This experimental trend for the torsional loading conditions often leads to the fact that the mean shear stress is not consider in the development of multiaxial fatigue criteria. Thus, the effect of a positive mean stress for loading levels inferior to the yield strength of the material is well documented in the scientific literature. However, when the maximum stresses exceed the yield strength of the material, the damage mechanisms that are involved are less understood.

However, other types of multiaxial loading conditions, such as biaxial tensile loads, have been less studied in terms of HCF. Some experimental results exist in the literature, but certain effects are still poorly understood such as the effect of the biaxiality ratio $k=\left(\frac{\sigma_{x x}(t)}{\sigma_{y y}(t)}\right)$ or the mean stress effect for biaxial tensile loading modes.

The aim of this article is to improve the understanding of the HCF behaviour, especially for applications involving high mean stress and biaxial stress states, so that these can be better taken into account in terms of fatigue modelling. A comparison is presented in the last section, which compares multiaxial fatigue models based on the normal stress to those that include the hydrostatic stress as parameters to take into account the spherical part of the cyclic stress tensor. The objective is to determine the best way to take into account a biaxial tensile stress state including mean stress.

Even though the notch effect is of great importance in the HCF assessment of real engineering components, ${ }^{14-16}$ notched fatigue is not addressed in this paper. It is a deliberate choice of the authors to focus on smooth specimens and to explain which criteria are the most relevant to account at the same time for the mean and the tension biaxial effects.

The following section is a literature review of selected multiaxial, HCF criteria. Particular emphasis is placed on the way in which these criteria model the mean stress effect and the effect of a tensile biaxial stress state. Models using the concept of elastic shakedown, coupled plasticity/damage at the mesoscopic scale, and energetic approaches are compared. It is shown that some loading conditions are correctly predicted by the majority of these criteria, while for others, the predictions are very different from one criterion to another.

\section{2 | THE MULTIAXIAL HCF CRITERIA INVESTIGATED}

To better understand the effects of the mean stress, a great deal of experimental data has been reported in the scientific literature. This is also true for biaxial tensile stress states; however, much less data are available in the literature. From this data, and sometimes from experimental observations of the associated fatigue damage mechanisms, many multiaxial HCF criteria have been proposed. The modelling approaches are varied, but as the HCF domain is often governed by the initiation life of fatigue cracks, only criteria established using a continuous solid mechanics framework are considered here.

The models presented below are multiaxial fatigue criteria that are supposed to take into account the loading conditions outlined above that are investigated in this work. In the scientific literature, many reviews and critical analyses of existing fatigue criteria have been published. ${ }^{17-20}$ In particular, Papadopoulos ${ }^{20}$ suggested that 
fatigue criteria can be divided into the following 4 categories:

- Strain-based criteria

- Stress-based criteria

- Energy-based criteria

- Criteria based on coupled plasticity-damage approaches

Generally, the strain-based criteria (and sometimes energy criteria) are well adapted to low-cycle fatigue where imposed strain tests are often performed and the level of cyclic plastic strain is nonnegligible. Stress-based approaches (and sometimes energy), as well as those based on plasticity-damage coupling (which have emerged more recently), are more often applied in the HCF domain. Therefore, in this work, the focus will be on the last 3 categories.

\section{1 | Stress-based criteria}

For this category of fatigue criteria, 3 different approaches can be defined.

- Criteria based on the critical plane concept

- Criteria based on stress invariants

- Criteria based on averaged stress values in an elementary volume

Many critical plane-based approaches have been proposed in the literature, such as the Matake criterion, ${ }^{21}$ the McDiarmid criterion, ${ }^{22}$ and the Susmel criterion. ${ }^{23}$ However, the aim of this paper is not to test all of them, but to investigate criteria considered to be representative of the different modelling families. Concerning the family of critical plane criteria, the aim is to evaluate the ingredients generally used and in particular to assess the robustness of criteria that use the hydrostatic stress in comparison to those based on the normal stress.

For the sake of simplicity and to avoid costly identification procedures, criteria are often expressed using 2 parameters. The first relates generally to the deviatoric part of the cyclic stress tensor and is often a shear stress (on a plane or averaged over an elementary volume) while the second reflects the spherical part of the cyclic stress tensor and is generally the normal stress (on a plane or averaged over an elementary volume) or the hydrostatic stress. The mean values and amplitudes of these quantities are determine and used according to the various criteria. Criteria using the hydrostatic stress are the most common. ${ }^{24-27}$

The multiscale approach applied to HCF emerged with the work of Dang Van ${ }^{28}$ and has since been used on numerous occasions including the work of Papadopoulos ${ }^{29}$ to better take into account effects of the loading paths.

Normal stress acting on material planes are sometimes used in critical plane approaches ${ }^{30}$ or via the integration over all possible crack initiation planes in an elementary volume. ${ }^{31}$ Morel and Huyen ${ }^{27}$ in particular have proposed a probabilistic approach that includes this type of integration.

\subsubsection{The Dang Van criterion}

In terms of $\mathrm{HCF}$ of polycrystalline metallic materials, it is widely accepted that mesoplasticity plays a key role in the initiation of fatigue cracks. Hence, the use of a multiscale approach is fully justified. Among these types of criteria, the Dang Van ${ }^{32}$ criterion is one of the most well known. It is a critical plane-type criterion that has a physical basis and is built around the postulate of elastic shakedown at both the mesoscopic and macroscopic scales. That is, in HCF, the macroscopic behaviour of the material remains globally elastic and only a few unfavourably oriented grains undergo plastic deformation. Dang Van proposed the following hypothesis: The multiscale approach is based on the assumption that under HCF loads a structure will not fail in fatigue if an elastic shakedown state is obtained at the macroscopic scale as well as at mesoscopic scale..$^{32}$

The approach developed by Dang Van consists of describing the plasticity at the mesoscopic scale by assuming that the Schmid yield criterion and linear isotropic hardening are appropriate. Finally, a mesoscale to macroscale transition is applied to establish the criterion at the macroscopic scale. The Lin-Taylor localisation model is used, which assumes that the strain at both scales is equivalent.

To take into account the negative role of the mean stress, Dang Van proposes to use the hydrostatic stress. At the mesoscopic scale, the criterion is expressed as a linear combination between the absolute value of the shear stress amplitude $\tau_{a}$ (in its shaken-down state, on the critical plane defined by is normal vector $\vec{n}$ ) and the hydrostatic stress.

$$
\max _{\vec{n}}\left\{\max _{t}\left[\left\|\tau_{a}(\vec{n}, t)\right\|+\alpha \Sigma_{h}(t)\right]\right\} \leqslant . \beta
$$

For each material plane $\vec{n}$, the critical point on the load path is determined using the maximisation in terms of time, $t$. The critical plane is then defined by the second maximisation.

The model parameters $\alpha$ and $\beta$ can be identified using 2 fatigue limits, usually the fully reversed push-pull fatigue strength, $s_{-1}$, and the fully reversed torsional fatigue strength, $t_{-1}$, are used.

$$
\alpha=\frac{t_{-1}-\frac{s_{-1}}{2}}{\frac{s_{-1}}{3}} \quad \text { and } \quad \beta=t_{-1} .
$$


For the particular case of uniaxial tensile loads, the criterion can be simplified to

$$
\Sigma_{x x, a}\left[\frac{1}{2}+\frac{\alpha}{3}\right]+\Sigma_{x x, m}\left[\frac{\alpha}{3}\right]=\beta .
$$

The Dang Van criterion is typically presented in the form of a diagram showing the loading path on the critical plane, in terms of the shear stress amplitude and the hydrostatic stress.

For uniaxial and biaxial tensile stresses, the presence of a mean stress diminishes the allowable shear stress.

For synchronous, in-phase biaxial tensile stresses, with a biaxiality ratio of $k=\frac{\Sigma_{y y}(t)}{\Sigma_{x x}(t)}$ where $k \in[0,1]$, the criterion can be written as

$$
\Sigma_{x x, a}\left[\frac{1}{2}+\frac{\alpha(1+k)}{3}\right]+\Sigma_{x x, m}\left[\frac{\alpha(1+k)}{3}\right]=\beta
$$

Many of the ingredients of this criterion have been recently justified by Charkaluk et al. ${ }^{33}$

\subsection{2 | The Papadopoulos criterion}

The approach proposed by Papadopoulos ${ }^{29,34}$ also uses the concept of elastic shakedown and the same localisation law as that used by Dang Van. However, Papadopoulos assumed that the crystals of a metallic aggregate follow a

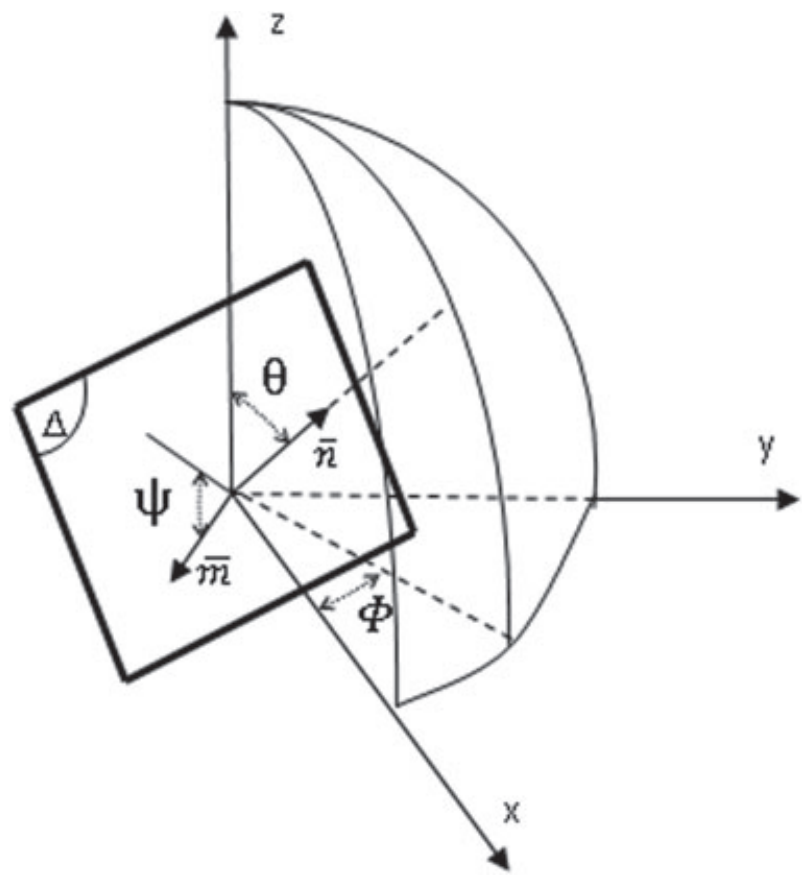

FIGURE 3 Spherical coordinate system used in the Papadopoulos criterion ${ }^{34}$

coordinate system $(\phi, \theta, \chi)$ can be defined by its unit vector, normal to the plane $\vec{n}$, and the unit vector $\vec{m}$ in the slip direction in the plane (see Figure 3). A triple integral is used by Papadopoulos to ensure that all possible slip systems are taken into account and to calculate the average value $\sqrt{\left\langle T_{a}^{2}\right\rangle}$ given by the following equation:

$$
\sqrt{\left\langle T_{a}^{2}\right\rangle}=\sqrt{5} \sqrt{\frac{1}{8 \pi^{2}} \int_{\phi=0}^{2 \pi} \int_{\theta=0}^{\pi} \int_{\chi=0}^{2 \pi}\left[T_{a}(\phi, \theta, \chi)\right]^{2} \sin (\theta) \mathrm{d} \chi \mathrm{d} \theta \mathrm{d} \phi .}
$$

combined isotropic and kinematic hardening rule when deforming plastically. For a slip system of a single crystal, he demonstrated that for a high number of cycles, there is an upper limit to the accumulated plastic strain that must not be crossed if fatigue failure is to be avoided and that this limit is proportional to the amplitude of the macroscopic resolved shear stress $T_{a}$ acting on the slip system.

Furthermore, given that the fatigue limit does not correspond to the complete absence of cracks, but more correctly, it implies the existence of a certain number of nonpropagating cracks that can be indefinitely supported. Papadopoulos proposed that it is preferable to define the fatigue limit in terms of an average value of the plastic strain, accumulated in all plastically deforming crystals, as opposed to a single slip system.

The average value of the macroscopic resolved shear stress associated with a slip system on an elementary material plane $\Delta$ passing through the origin $O$ in a spherical
Papadopoulos proposed to use a second parameter $\left\langle\Sigma_{n}\right\rangle$ to take into account the spherical part of the stress tensor and to account for the mean stress effect. This parameter is the average value of the normal stress on each material plane and is given by the equation below. It should be noted that this quantity is equivalent to the hydrostatic stress $\Sigma_{h}$ :

$$
\left\langle\Sigma_{n}\right\rangle=\frac{1}{4 \pi} \int_{\phi=0}^{2 \pi} \int_{\theta=0}^{\pi} \Sigma_{N}(\theta, \phi) \sin (\theta) \mathrm{d} \theta \mathrm{d} \phi=\Sigma_{h} .
$$

The fatigue criterion is written as a linear combination of the above 2 parameters:

$$
\sqrt{\left\langle T_{a}^{2}\right\rangle}+\alpha \Sigma_{h, \max }<\beta,
$$

where $\alpha$ and $\beta$ are 2 material constants that can be identified using the fully reversed uniaxial fatigue limit $\left(s_{-1}\right)$ and the fully reversed torsional fatigue limit $\left(t_{-1}\right)$. 
For the particular case of uniaxial tensile loads, the criterion can be simplified to

$$
\Sigma_{x x, a}\left[\frac{1}{\sqrt{3}}+\frac{\alpha}{3}\right]+\Sigma_{x x, m}\left[\frac{\alpha}{3}\right]=\beta .
$$

For synchronous, in-phase loads biaxial tensile stresses, with a biaxiality ratio of $k=\frac{\Sigma_{y y}(t)}{\Sigma_{x x}(t)}$ where $k \in[0,1]$, the criterion can be written as

$$
\begin{aligned}
& \Sigma_{x x, a}\left[\frac{1}{\sqrt{3}}\left(1+k^{2}-k\right)^{\frac{1}{2}}+\frac{\alpha(1+k)}{3}\right] \\
& +\Sigma_{x x, m}\left[\frac{\alpha(1+k)}{3}\right]=\beta .
\end{aligned}
$$

\subsection{3 | The Liu and Zenner criterion}

The Liu and Zenner criterion ${ }^{31,35}$ is part of the family of criteria based on average stress values within an elementary volume. ${ }^{36-38}$ The typical ingredients of these criteria are average quantities within an elementary volume $V$ of the shear and normal stresses acting on a material plane $\Delta$. In general, these average quantities are described through a double integral. The Liu and Zenner criterion can be written as

$$
b n=\frac{s_{-1}^{2}-\left(\frac{s_{0}}{2}\right)^{2}-\frac{4}{21} \operatorname{am}\left(\frac{s_{0}}{2}\right)^{4}}{\frac{15}{14}\left(\frac{s_{0}}{2}\right)^{3}} .
$$

The fact that 4 fatigue strengths are required to identify the model parameters is a limiting factor for the wide spread use of the model.

For the case of uniaxial tensile loads, the criterion can be simplified to

$$
\left[\Sigma_{x x, a}^{2}\left(1+\frac{a m}{21} 4 \Sigma_{x x, m}^{2}+\frac{3 b n}{14} 5 \Sigma_{x x, m}\right)\right]^{\frac{1}{2}}=s_{-1} .
$$

For synchronous, in-phase biaxial tensile stresses, with a biaxiality ratio of $k=\frac{\Sigma_{y y(t)}}{\Sigma_{x x(t)}}$ where $k \in[0,1]$, the complex formulation of the criterion is described by Liu and Zenner. ${ }^{31}$

\subsection{4 | The Morel and Huyen criterion}

In the model developed by Morel and Huyen, ${ }^{27,39}$ it is assumed that when a condition of plastic shakedown is achieved in one (or more) grains, fatigue failure is inevitable. To calculate the global probability of failure of the structure, it is sufficient to sum the failure probabilities

$$
\Sigma_{V A}=\sqrt{\frac{15}{8 \pi} \int_{\phi=0}^{\pi} \int_{\theta=0}^{2 \pi} a T_{a}^{2}\left(1+m T_{m}^{2}\right)+b \Sigma_{n, a}^{2}\left(1+n \Sigma_{n, m}^{2}\right) \sin (\theta) \mathrm{d} \theta \mathrm{d} \phi}<s_{-1} .
$$

This criteria takes into account the mean values and the amplitudes of the normal stress and the shear stress on each material plane. The parameters $a, b, n$, and $m$ are material parameters that can be identified using 4 uniaxial fatigue limits. $S_{-1}$ and $t_{-1}$ for a load ratio equal to $R=-1$, and $s_{0}$ and $t_{0}$, for a load ratio equal to $R=0$. for each of the grains contained in the loaded volume. By introducing a Weibull ${ }^{40}$ distribution to describe the elastic shakedown threshold at the mesoscopic scale and by using the weakest link hypothesis to consider all possible directions and the total stressed volume, the failure probability is described by

$$
P_{f}=1-\exp \left[-\frac{1}{V_{o}} \int_{\Omega}\left\{\int_{\phi=0}^{2 \pi} \int_{\theta=0}^{\pi} \int_{\chi=0}^{2 \pi}\left(\frac{T_{a}(\theta, \phi, \chi)}{T_{o}}\right)^{m} \sin (\theta) \mathrm{d} \chi \mathrm{d} \theta \mathrm{d} \phi\right\} \mathrm{d} V\right]
$$

$$
\begin{aligned}
& a=\frac{1}{5}\left[3\left(\frac{s_{-1}}{t_{-1}}\right)^{2}-4\right], \\
& b=\frac{1}{5}\left[6-2\left(\frac{s_{-1}}{t_{-1}}\right)^{2}\right], \\
& a m=\frac{s_{-1}^{2}-\left(\frac{s_{-1}}{t_{-1}}\right)^{2}\left(\frac{t_{0}}{2}\right)^{2}}{\frac{12}{7}\left(\frac{s_{0}}{2}\right)^{4}},
\end{aligned}
$$

where $T_{a}$ is the amplitude of the macroscopic resolved shear stress acting on a slip system. The spherical coordinates $(\phi, \theta)$ are used to describe the slip plane normal vector $\vec{n}$ and a third angle, $\chi$, is used to define the shear direction in the plane. $T_{0}$ is the scale factor of the Weibull distribution, $m$ is the Weibull exponent, and $V_{0}$ is the reference volume. It is generally accepted that both the mean and the amplitude of the stress, normal to the slip plane, have an influence on crack initiation. To take into account both of these loading parameters, the following scale factor, $T_{0}$, is used: 


$$
T_{o}=T_{o}^{\prime} \frac{1-\gamma \Sigma_{n, m}(\theta, \phi)}{1+\alpha \frac{\Sigma_{n, a}(\theta, \phi)}{\tau_{a}(\theta, \phi, \psi)}},
$$

where $\Sigma_{n, m}(\theta, \phi)$ and $\Sigma_{n, a}(\theta, \phi)$ are the mean and the amplitude of the normal stress acting on the slip plane. $\gamma$ and $\alpha$ are the normal stress sensitivity coefficients. The ratio $\left(\Sigma_{n, a}(\theta, \phi) /\left(\tau_{a}(\theta, \phi, \chi)\right)\right.$ is used to define the degree of triaxiality and has the effect of reducing the scale factor. To simplify the notation, the parameter $I_{m}$ is introduced and is given by

$I_{m}=\int_{\phi=0}^{2 \pi} \int_{\theta=0}^{\pi} \int_{\psi=0}^{2 \pi}\left(\frac{\chi_{a}(\theta, \phi, \psi)}{1-\gamma \Sigma_{n, m}(\theta, \phi) X_{a}}\right)^{m} \sin (\theta) \mathrm{d} \psi \mathrm{d} \theta \mathrm{d} \phi$,

where $\left.\chi_{a}(\theta, \phi, \psi)=T_{a}(\theta, \phi, \psi)\right)+\alpha \Sigma_{n, a}(\theta, \phi)$ and $X_{a}=$ $\max _{\theta, \phi, \psi}\left[X_{a}(\theta, \phi, \psi)\right]$.

The expression for the total probability of failure of the structure then becomes

$$
P_{f}=1-\exp \left[-\frac{1}{V_{0}} \int_{V} \frac{X_{a}^{m} I_{m}}{\left(T_{0}^{\prime}\right)^{m}} \mathrm{~d} V\right] .
$$

For multiaxial loading conditions, it has been shown by the authors that this model is capable of accurately predicting certain effects relative to the loading path, particularly for combined tension-torsion loads and biaxial tensile loads. The effects of out-of-phase loads and different loading frequencies are also correctly accounted for by this criterion.

The authors also discuss the possibility of using the hydrostatic stress $\Sigma_{H}$ instead of the normal stress to simplify the calculations.

In this work, the criteria using the normal stress is referred to as "Morel and Huyen-Nor." and the same criteria based on the hydrostatic stress is referred to as "Morel and Huyen-Hyd." When the hydrostatic stress is used, the scale factor is written as

$$
T_{o}=T_{o}^{\prime} \frac{1-\gamma^{\prime} \Sigma_{h, m}}{1+\alpha \frac{\Sigma_{h, a}}{\tau_{a}}} .
$$

This expression and detail of this model can be found in Thu. ${ }^{39}$

\section{2 | Energy-based criteria}

Energy-based multiaxial fatigue criteria can be divided into 3 groups, ${ }^{41}$ depending on the kind of strain energy density per cycle, which is assumed as the damage parameter, that is,

- criteria based on the elastic strain energy

- criteria based on the plastic strain energy
- criteria based on the sum of the elastic and plastic strain energy

For the last category, the strain energy density approach proposed by Berto et $\mathrm{al}^{42}$ or Lazzarin et $\mathrm{al}^{43}$ has been extensively used to take into account the notch effect coupled with the finite element method. However, as this paper does not specifically aim to investigate the notch effect, the following section is focused on only 2 energy approaches: one proposed by Froustey et $\mathrm{al}^{44}$ and the second by Palin-Luc ${ }^{45}$ and Banvillet. ${ }^{46}$

\subsection{1 | The Froustey and Lasserre criterion}

Froustrey et $\mathrm{al}^{44}$ proposed an energy-based macroscopic model based on the accumulated strain energy density. The aim of this criterion is not to predict the propagation direction of a fatigue crack but to predict multiaxial fatigue crack initiation. The authors consider the mean value of the elastic strain energy density $W$ defined by Equation 21 over one loading period $T$ at point $M$ in the component. $\Sigma_{i j}$ and $\varepsilon_{i j}^{e}$ are time functions of the stress tensor and the elastic strain tensor, respectively, at the considered point.

$$
W=\frac{1}{T} \int_{0}^{T} \frac{1}{2} \Sigma_{i j}(t) \varepsilon_{i j}^{e}(t) \mathrm{d} t .
$$

As proposed by Tsybanev, ${ }^{47}$ a complete loading cycle is considered to distinguish between rotating bending and plane bending. In the HCF regime, the material remains elastic at the macroscopic scale, thus $W$ is also the mean value of the total strain energy density.

For all periodic loads, the stress tensor can be decomposed into an amplitude, $\Sigma_{i j, a}(t)$, and a mean value, $\Sigma_{i j, m}(t)$. The same can be done for the strains, $\varepsilon_{i j}(t)=\varepsilon_{i j, a}(t)+\varepsilon_{i j, m}$. Also, the total strain energy density can be expressed as the sum of the alternating part and a static term, $W=W_{a}+W_{m}$, where

$W_{a}=\frac{1}{T} \int_{0}^{T} \frac{1}{2} \Sigma_{i j, a}(t) \varepsilon_{i j, a}^{e}(t) \mathrm{d} t \quad$ and $\quad W_{m}=\frac{1}{2} \Sigma_{i j, m} \varepsilon_{i j, m}^{e}$.

As the authors consider that fatigue crack initiation depends on both the hydrostatic stress and the alternating shear stress, they have chosen to consider separately the spherical part of the alternating strain energy density $W_{s a}$ and the deviatoric part $W_{d a}$ (see Equation 23). Similarly, the spherical Wsm and deviatoric parts $W_{d m}$ of the static strain energy density $W_{m}$ are considered separately (see Equation 24). 


$$
\begin{gathered}
W_{s a}=\frac{1-2 v}{6 E} \frac{1}{T} \int_{0}^{T} I_{1, a}^{2}(t) \mathrm{d} t \\
\text { and } \\
W_{d a}=\frac{1+v}{E} \frac{1}{T} \int_{0}^{T} J_{2, a}(t) \mathrm{d} t, \\
W_{s m}=\frac{1-2 v}{6 E} I_{1, m}^{2} \quad \text { and } \quad W_{d m}=\frac{1+v}{E} J_{2, m},
\end{gathered}
$$

where $I_{1, a}$ and $I_{1, m}$ are the amplitude and mean values of the first invariant of the stress tensor, and $J_{2, a}$ or $J_{2, m}$ are the amplitude and mean values of the second invariant of the stress deviator.

The degree of triaxiality is defined as per De Leiris ${ }^{48}$ and is expressed as the ratio between the spherical and total values of $W$ for both the mean and the amplitude (see Equation 25).

$$
d T_{a}=\frac{W_{s a}}{W_{a}} \quad \text { and } \quad d T_{m}=\frac{W_{s m}}{W_{m}} .
$$

The influence of the degree of triaxiality is described for a given mean load by the following normalised function $F$ varying between 0 and 1 :

$$
\frac{W_{a}}{W d a_{e q}}=F\left(d T_{a}, \beta\right)=\frac{1}{1-d T_{a}}\left\{1-\frac{1}{\beta} \ln \left[1+d T_{a}\left(e^{\beta}-1\right)\right]\right\},
$$

where $W d a_{e q}$ is the equivalent distortion energy generated at the endurance limit by a pure distortion load (ie, torsion) $(d T a=0)$. The parameter $\beta$ is a material dependent constant defining the stress triaxiality sensibility of the material.

For the particular cases of uniaxial tensile loads and synchronous, in-phase biaxial tensile loads with a biaxiality ratio of $k=\frac{\Sigma_{y y(t)}}{\Sigma_{x x(t)}}$ where $k \in[0,1]$, the criterion can be written as ${ }^{49}$

$$
\left(\frac{\Sigma_{x x, a}}{S_{-1} J^{2}}\right)^{2}+\left(\frac{\Sigma_{x x, m}}{R_{m} K^{2}}\right)^{2}=1,
$$

where $J$ and $K$ are 2 parameters depending on the loading type and the material. For the case of uniaxial tensile loads, $J=K=1$ and the criterion becomes equivalent to the Marin ${ }^{50}$ criterion.

From Equation 27, it can be seen that the mean stress correction is not linear. Hence, it is expected that good predictions will be obtained for ductile materials; however, it is probable that the predictions for brittle or fragile materials (where $\frac{t_{-1}}{s_{-1}} \approx 1$ ) will be overestimated.

Concerning the case of biaxial tensile loads, the same trend is observed for the mean stress effect as per the uniaxial case. Except the parameters $J$ and $K$ depend on the biaxiality ratio:

$$
J^{2}=\frac{F\left(d T_{a} \beta\right) / F\left(d T_{a, \text { uniax }}, \beta\right)}{1+\left(\frac{\Sigma_{y y, a}}{\Sigma_{x x, a}}\right)^{2}-2 v\left(\frac{\Sigma y y, a}{\Sigma x x, a}\right) \cos \left(\beta_{x x}-\beta_{y y}\right)}
$$

and

$$
K^{2}=\frac{F\left(d T_{m}, \beta\right) / F\left(d T_{\text {m,uniax }}, \beta\right)}{1+\left(\frac{\Sigma_{y y, m}}{\Sigma_{x x, m}}\right)^{2}-2 v\left(\frac{\Sigma_{y y, m}}{\Sigma_{x x, m}}\right)} .
$$

For uniaxial tension, $d T_{a, \text { uniax }}$ is equal to $1 / 9$, and for the biaxial tension case, $d T_{a}$ is

$$
d T_{a}=\frac{1-2 v}{3} \frac{1+\left(\frac{\Sigma_{x x, a}}{\Sigma_{y y, a}}\right)^{2}+2\left(\frac{\Sigma_{x x, a}}{\Sigma_{y y, a}}\right) \cos \left(\beta_{x x}-\beta_{y y}\right)}{1+\left(\frac{\Sigma_{x x, a}}{\Sigma_{y y, a}}\right)^{2}-2 v\left(\frac{\Sigma_{x x, a}}{\Sigma_{y y, a}}\right) \cos \left(\beta_{x x}-\beta_{y y}\right)} .
$$

\subsection{2 | The Lamefip criterion}

The criterion referred to as the "Lamefip criterion" is presented here in the version discussed by Benabes ${ }^{51}$ and Saintier et al. ${ }^{52}$ This model takes into account the effect of stress and strain gradients on the fatigue strength. It is based on the concept of a volume of influence around a critical point, in which the strain work density supplied to the material over a loading period or sequence is used. A threshold value of $W_{f}^{*}$ is introduced, which represents the minimum value of the strain work density required for creating, after many cycles, irreversible damage in the material.

The criterion is constructed from 3 principal hypotheses:

- The strain work density, to which the material is subjected, is considered to be the driving force for fatigue damage initiation.

- The strain work density is calculated as the sum of the contribution of each term of the stress and strain tensors.

- The strain work density is determined after the material is elastically shaken down (as assumed in HCF).

The strain energy density supplied to the material over a loading cycle or a sequence of duration $\mathrm{T}$, at point $\mathrm{M}$ is a function of time, and is given by

$$
W_{f}(M)=\sum_{i=1}^{3} \sum_{j=1}^{3} \int_{T}\left\langle\Sigma_{i j}(M, t) \dot{\varepsilon}_{i j}^{e}(M, t)\right\rangle \mathrm{d} t,
$$

where $\dot{\varepsilon}_{i j}^{e}(M, t)$ and $\Sigma_{i j}(M, t)$ are the stress and elastic strain tensors at point $\mathrm{M}$ and are functions of time. 
When stress gradient are present, the authors assume that the threshold stress defines the volume of material influencing fatigue crack initiation $V^{*}\left(C_{i}\right)$. All potentially critical points, $C_{i}$, or locations where the supplied strain work density $W_{f}$ are local maxima are considered. Around
$F\left(d T\left(C_{i}\right), \beta\right)=\frac{1}{1-d T\left(C_{i}\right)}\left\{1-\frac{1}{\beta} \ln \left[1+d T\left(C_{i}\right)\left(e^{\beta}-1\right)\right]\right\}$.

The threshold value $W_{f s o l l}^{*}$ is also a function of the stress trixiality using the function $F$ :

$$
W_{\text {fsoll }}^{*}=F\left(d T\left(C_{i}\right)_{\text {soll }}, \beta\right) . W_{\text {ftorsion }}=W_{\text {funiax }}^{*}\left(C_{i}\right) \frac{F\left(d T\left(C_{i}\right)_{\text {soll }}, \beta\right)}{F\left(d T_{\text {uniax }}, \beta\right)} .
$$

each one of these potentially critical points, the influence volume $V^{*}\left(C_{i}\right)$ is defined by the volume where the damaging work is not zero (or where $W_{f}(M)>W_{f}^{*}$ ). The damage parameter is defined by

$$
\bar{\omega}_{f}\left(C_{i}\right)=\frac{1}{V^{*}\left(C_{i}\right)} \int_{\left.V_{(}^{*} C_{i}\right)}\left[W_{f}(M)-W_{f}^{*}\right] \mathrm{d} V .
$$

For a uniaxial stress state loaded at the fatigue limit, the author postulates that the quantity $\bar{\omega}_{f}\left(C_{i}\right)$ depends on the material and is noted $\bar{\omega}_{\text {funiax }}^{D}$ ). For a uniaxial stress state, the values of $\sigma^{*}, W_{f}^{*}$ and $\bar{\omega}_{\text {funiax }}^{D}$ can be expressed by the following equations:

$$
\begin{gathered}
\sigma^{*}=\sqrt{2\left(s_{-1}\right)^{2}-\left(f_{\text {rot }-1}\right)^{2}}, \\
W_{f}^{*}=\frac{2\left(s_{-1}\right)^{2}-\left(f_{\text {rot }-1}\right)^{2}}{E}, \\
\bar{\omega}_{\text {funiax }}^{D}=\frac{\left(f_{\text {rot-1 }}\right)^{2}-\left(s_{-1}\right)^{2}}{E},
\end{gathered}
$$

where $f_{\text {rot-1 }}$ and $s_{-1}$ are the fatigue limits in fully reversed rotating bending and in fully reversed tension-compression.

To take into account the sensitivity of the material to the stress triaxiality, a triaxiality parameter is define at each material point $\mathrm{M}$. This parameter is the ratio between the spherical elastic strain energy and the instantaneous total elastic strain energy and is defined as

$$
d T(M)=\frac{d W_{f}^{V}(M)}{d W_{f}(M)},
$$

As per the C. et $\mathrm{al}^{44}$ criterion, an empirical function is used $F\left(d T\left(C_{i}\right)\right.$, ) where $d T$ defines the degree of stress triaxiality and $\beta$ is a material parameter. For a given material, this function represents the evolution, versus $d T$, of the ratio of the strain work density value at the endurance limit, and the corresponding value in torsion.

$$
F\left(d T\left(C_{i}\right)_{\text {soll }}, \beta\right)=\frac{W_{f}^{D}\left(C_{i}\right)_{\text {soll }}}{W_{f}^{D}\left(C_{i}\right)_{\text {torsion }}},
$$

The volume influencing fatigue crack initiation is defined around each critical point for any loading condition. By assuming that all the critical points have an effect on the material fatigue damage, the mean value over $V^{*}$ of the damaging part of $W_{f}$ is

$$
\bar{\omega}_{f}\left(C_{i}\right)=\frac{1}{V^{*}\left(C_{i}\right)} \int_{V^{*}\left(C_{i}\right)}\left[W_{f}(M)-W_{f}^{*}\left(C_{i}\right)\right] d V .
$$

Finally, the criterion assumes that there is no fatigue crack initiation for any multiaxial loading condition if the following expression is satisfied ${ }^{46}$ :

$$
\bar{\omega}_{f}\left(C_{i}\right)<\bar{\omega}_{f}^{D}\left(C_{i}\right)
$$

where $\bar{\omega}_{f}^{D}\left(C_{i}\right)$ is the threshold value of $\bar{\omega}_{f}\left(C_{i}\right)$ at the endurance limit. It can be calculated for any loading condition by the following equation:

$$
\bar{\omega}_{f}^{D}\left(C_{i}\right)=\frac{F\left(d T\left(C_{i}\right)_{\text {soll }} \beta\right)}{F\left(d T_{\text {uniax }} \beta\right)} \bar{\omega}_{\text {uniax }}^{D} .
$$

\section{3 | CRITERIA PREDICTIONS}

Following the above presentation of different HCF criteria, the criteria predictions will be analysed in this section in terms of their ability to predict the fatigue behaviour of the alloy steel 34CrMo4 under different loading conditions. The objectives are

- to better understand the limits of each criterion and

- to identify the trends concerning the way in which the different criteria treat different loading conditions.

It should be noted that in this section, the criteria predictions are not directly compared to experimental results, but the trends obtained for each criterion are compared. The initial focus is placed on uniaxial loads and the effect of the mean stress. Secondly, in-phase, combined tension-torsion loads and biaxial tensile loads are considered. Finally, the mean stress effect on these multiaxial conditions is investigated.

To use the fatigue criteria, the choice is made to base the comparison on one metallic material, the $34 \mathrm{CrMo} 4$ 
TABLE 1 Mechanical properties of the $34 \mathrm{CrMo} 4 \mathrm{steel}^{7}$

\begin{tabular}{lllll}
$\boldsymbol{t}_{\mathbf{- 1}}$ & $\boldsymbol{s}_{\mathbf{- 1}}$ & $\boldsymbol{s}_{\boldsymbol{o}}$ & $\Sigma_{\boldsymbol{U T S}}$ & $\Sigma_{\boldsymbol{Y}}$ \\
\hline $284 \mathrm{MPa}$ & $382 \mathrm{MPa}$ & $600 \mathrm{MPa}$ & $902 \mathrm{MPa}$ & $706 \mathrm{MPa}$
\end{tabular}

high-strength steel, whose mechanical properties are presented in Table 1. With these values, taken from the literature, ${ }^{7}$ it is possible to make predictions using all of the previously discussed criteria for all of the loading conditions investigated.

Note that to identify the Liu and Zenner criterion, the torsional fatigue strength for a load ratio of $R=0$ is required $\left(t_{0}\right)$. The empirical relation proposed by the authors is used to estimate $t_{0}$. That is,

$$
t_{0}=\frac{4 t_{-1}}{\frac{2 s_{-1}}{S_{0}}+1} .
$$

For the Morel and Huyen criterion and the LAMEFIP criterion, the typical parameters proposed by the authors have been used. That is, for the Morel and Huyen criterion, the parameter $m$ or the Weibull exponent representing the scatter is chosen to be equal to 20 . The authors indicate that this is a common value for steels. Concerning LAMEFIP criterion, the ratio between the fatigue strength in rotating bending to the uniaxial tension-compression fatigue strength for a load ratio of $R=-1$ is assumed to be 0.9 . Moreover, it is assumed that the stress field is uniform and that the critical volume is equal to the total volume of the specimen.

\section{1 | Uniaxial loads including mean stress}

Initially, attention is focused on the case of uniaxial tensile loads including a mean stress, in which only one component of the stress tensor is present. Assuming a sinusoidal evolution of this term $\Sigma_{x x}(t)$, the stress is

$$
\overline{\bar{\Sigma}}(t)=\left[\begin{array}{ccc}
\Sigma_{x x}(t) & 0 & 0 \\
0 & 0 & 0 \\
0 & 0 & 0
\end{array}\right] \quad \text { where } \quad \Sigma_{x x, m}+\Sigma_{x x, a} \sin (\omega t) .
$$

The predictions from the different criteria are shown in Figure 4 in the form of a normalised Haigh diagram. The Goodman and Gerber empirical criteria are also plotted in this diagram as well as the conditions where the maximum stress is equal to the ultimate tensile stress and the yield stress of the material. The $\mathrm{x}$-axis of the diagram has been normalised by the ultimate tensile strength $\left(\Sigma_{U T S}\right)$ and the $\mathrm{y}$-axis by the fully reversed uniaxial fatigue strength $\left(s_{-1}\right)$.

It is important to note that as a general rule, these criteria are not meant to take into account stress levels that exceed the yield stress of the material. Also, only the Goodman and Gerber criteria predict zero stress amplitude when

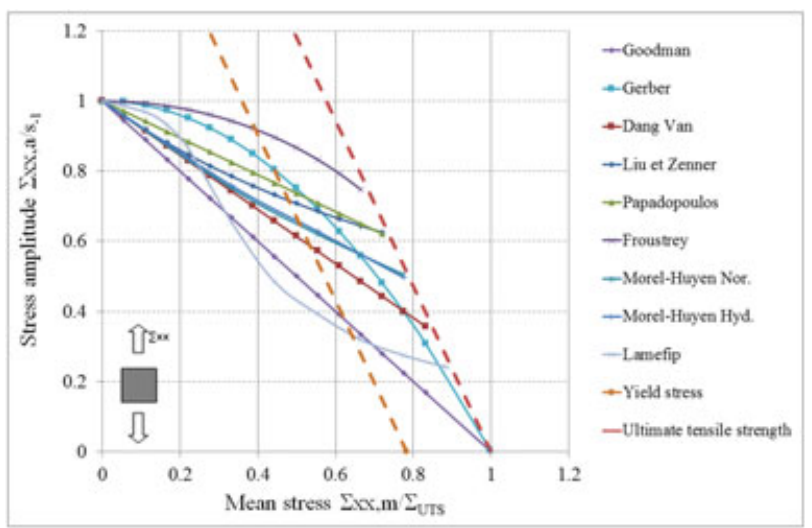

FIGURE 4 Normalised Haigh diagram for the material 34CrMo4 [Colour figure can be viewed at wileyonlinelibrary.com]

the mean stress is equal to the ultimate tensile stress. The most important feature of this graph is the high degree of variation in the predictions for this one steel.

It can be seen that the predictions from most of the criteria fall between the Goodman and the Gerber predictions. It should be noted that these criteria are based on the assumption that the material remains globally elastic in the HCF regime. Hence, the validity of the criteria is questionable when the maximum stress exceeds the yield stress of the material. The Lamefip criterion shows most unique form with a sigmoidal shape containing several changes in curvature.

Two different trends concerning the mean stress effect can be noted:

- The first is a linear decrease in the fatigue strength with the mean stress, such as the Goodman criterion. However, depending on the criterion, the slope of the line is very different. Figure 5A shows the predictions for the models belonging to this category.

- The second is a non-linear dependence on the mean stress (see Figure 5B. In this category, the prediction curves have a convex (Gerber and Froustrey criteria), or a concave form (Liu and Zenner criterion), or a sigmoidal form (the Lamefip criterion).

\subsection{Combined tension-torsion loads}

The first type of stress biaxiality investigated is combined in-phase synchronous sinusoidal tension-torsion loads with a stress ratio of $R=-1$. The degree of biaxiality is defined by the biaxiality ratio given by $k=\frac{\Sigma_{x y}}{\Sigma_{x x}}$. Experimental tests for this type of loading condition are performed either by bending-torsion or tension-torsion loads. The cyclic stress state can be described by 

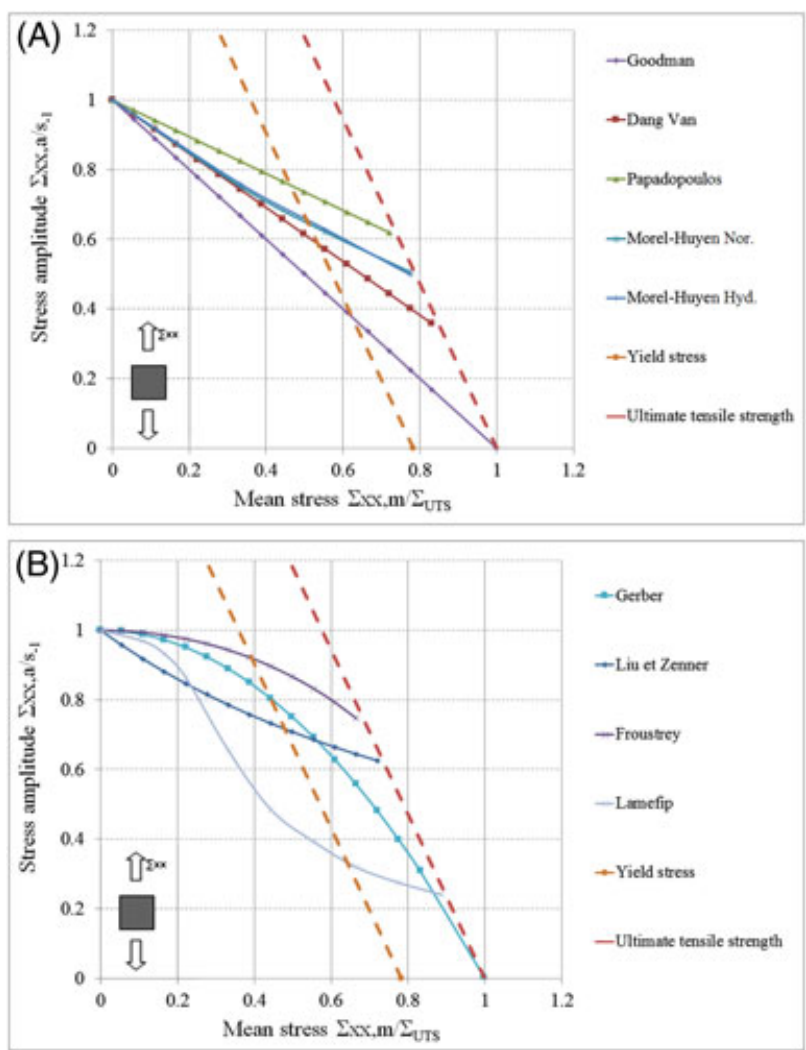

FIGURE 5 Normalised Haigh diagram showing A, the criteria with a linear trend and $\mathrm{B}$, the criteria with a non-linear trend [Colour figure can be viewed at wileyonlinelibrary.com]

$$
\underline{\underline{\Sigma}}(t)=\left[\begin{array}{ccc}
\Sigma_{x x}(t) & \Sigma_{x y}(t) & 0 \\
\Sigma_{x y}(t) & 0 & 0 \\
0 & 0 & 0
\end{array}\right]
$$

where

$$
\begin{aligned}
& \Sigma_{x x}(t)=\Sigma_{x x, a} \sin (\omega t), \\
& \Sigma_{x y}(t)=\Sigma_{x y, a} \sin (\omega t) .
\end{aligned}
$$

The predictions for the different criteria, shown in Figure 6, clearly highlight the fact that all of the criteria predict similar behaviour for this loading type. It is important to note however that this observation is less true for out-of-phase, nonsynchronous loads. ${ }^{39}$

\section{3 | Equibiaxial loads}

The second multiaxial loading condition investigated is in-phase, synchronous, sinusoidal biaxial stresses characterised by 2 normal stress components. In this case, the biaxiality ratio is given by $k=\frac{\Sigma_{y y}(t)}{\Sigma_{x x}(t)}$ and can vary between 0 and 1 . The case where $k=1$ corresponds to equibiaxial tension. This cyclic stress state can be described by

$$
\underline{\underline{\Sigma}}(t)=\left[\begin{array}{ccc}
\Sigma_{x x}(t) & 0 & 0 \\
0 & \Sigma_{y y}(t) & 0 \\
0 & 0 & 0
\end{array}\right]
$$

where

$$
\begin{gathered}
\Sigma_{x x}(t)=\Sigma_{x x, a} \sin (\omega t), \\
\Sigma_{y y}(t)=k \Sigma_{x x}(t) .
\end{gathered}
$$

Firstly, the case where there is no mean stress for either stress component is investigated. Figure 7 shows the criteria predictions, represented in terms of the stress amplitude in the $\mathrm{x}$ direction normalised by the uniaxial fatigue strength $\frac{\Sigma_{x x, a}}{s_{-1}}$ as a function of the biaxiality ratio. From this figure, several trends can be observed:

- Almost all of the models predict a negative effect of the biaxiality for high biaxiality ratios.

- Contrary to the tension-torsion case, the different criteria result in very varied predictions.

- For the Dang Van and Liu and Zenner criteria, the damaging effect of an increasing biaxiality ratio is almost linear.

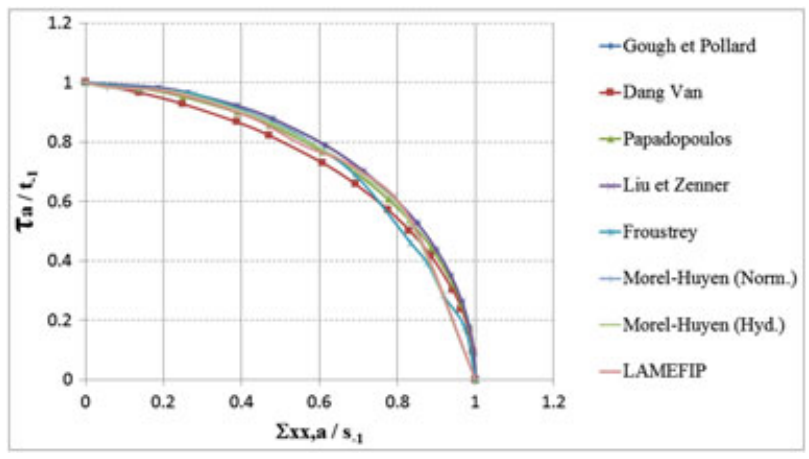

FIGURE 6 Predictions from the different criteria for combined in-phase, synchronous sinusoidal tension-torsion loads [Colour figure can be viewed at wileyonlinelibrary.com]

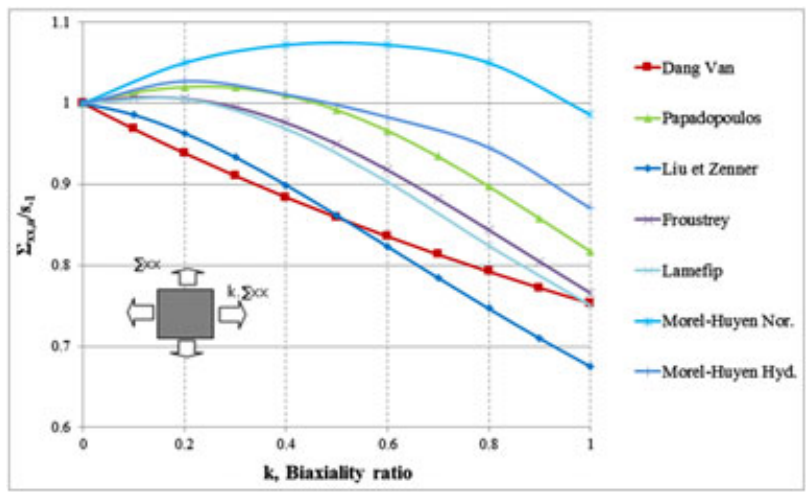

FIGURE 7 Predictions from the different criteria for in-phase, synchronous sinusoidal biaxial stress states [Colour figure can be viewed at wileyonlinelibrary.com] 
- For some criteria, there is an increase in fatigue strength at low biaxiality ratios followed by a sharp decrease up to the equibiaxial state $(k=1)$. The Froustrey, Lamefip, More and Huyen (Hyd.), and the Papadopoulos criteria present this type of behaviour.

- The Morel and Huyen (Normal) criterion is the only one to predict a beneficial effect of the biaxiality for almost all the biaxiality ratio range. This beneficial effect is a maximum for a biaxiality ratio of $k=0.5$.

Contrary to the case of combined tension-torsion loads, Figure 7 highlights the fact that different criteria investigated predict very different trends for this loading condition.

Finally, the case of equibiaxial tensile stresses $(k=1)$ including the mean stress effect is investigated. It is assumed that the stress components in the $\mathrm{x}$ and $\mathrm{y}$ directions are in-phase, synchronous, and sinusoidal, given by

$$
\overline{\bar{\Sigma}}(t)=\left[\begin{array}{ccc}
\Sigma_{x x}(t) & 0 & 0 \\
0 & \Sigma_{y y}(t) & 0 \\
0 & 0 & 0
\end{array}\right]
$$

where

$$
\begin{gathered}
\Sigma_{x x}(t)=\Sigma_{x x, m}+\Sigma_{x x, a} \sin (\omega t), \\
\Sigma_{y y}(t)=k \Sigma_{x x}(t) .
\end{gathered}
$$

Figure 8 shows the prediction results for equibiaxial stresses, including the effect of positive mean stresses. The predictions are shown in the form of a normalised Haigh diagram. The y-axis shows the predicted stress amplitude normalised by the uniaxial fatigue strength $\frac{\Sigma_{x x, a}}{s_{-1}}=\frac{\Sigma_{y y, a}}{s_{-1}}$. The $\mathrm{x}$-axis is the mean stress normalised by the ultimate tensile strength of the material $\frac{\Sigma_{x x, m}}{\Sigma_{U T S}}=\frac{\Sigma_{y y, a}}{\Sigma_{U T S}}$. It can be seen that
- All of the criteria predict a detrimental effect of tensile mean stresses for this loading condition. Note that when the normalised mean stress value is equal to zero, the predictions are the same as those shown in Figure 7 for a biaxiality ratio of $k=1$.

- Only the Morel and Huyen (Normal) criterion predicts no effect of the stress biaxiality without mean stress.

- With increasing mean stress, the variations between each criteria increase to the point that it is impossible to identify a common trend.

It is clear that the predictions for biaxial stress states, combined with the mean stress, are very different depending on the criterion used. Hence, to achieve good predictions, greater attention should be given to this type of loading condition.

\section{4 | CONSIDERATION OF BIAXIAL TENSION IN MULTIAXIAL CRITERIA}

In the scientific literature, no general consensus can be found concerning the effect of a biaxial stress state on the fatigue life and fatigue crack growth. Gaur et $\mathrm{al}^{53}$ summarises the different effects observed for this type of loading condition. Some authors report a detrimental effect. ${ }^{54-57}$ Inversely, a certain number of authors report a beneficial effect. ${ }^{58-61}$ Finally, a neutral effect is reported by others. ${ }^{62-65}$

It can be concluded from this lack of consensus that the biaxial loading condition, with or without mean stress, merits further investigation.

In this section, the criteria discussed in this paper are tested against experimental data taken from the literature

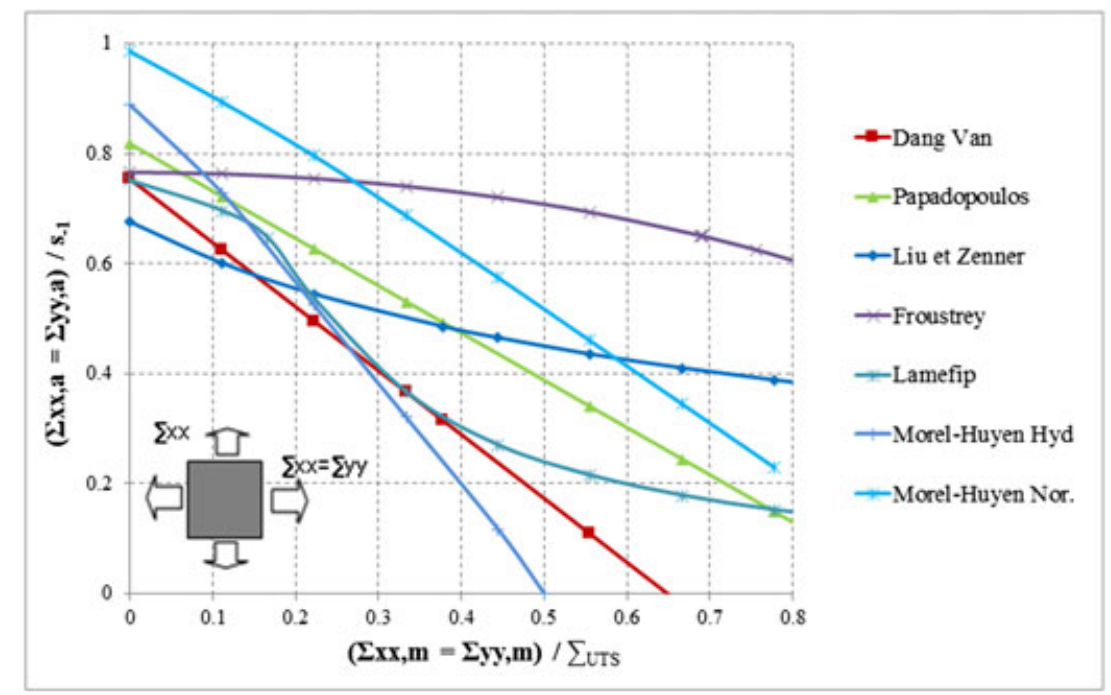

FIGURE 8 Predictions from the different criteria for in-phase, synchronous sinusoidal equibiaxial stress states including the mean stress effect [Colour figure can be viewed at wileyonlinelibrary.com] 
in terms of biaxial stress states for six engineering materials. The materials and references are given in Table 2 . Only the following 5 criteria are investigated: Dang Van, Papadopulos, Morel and Huyen (Hyd.), Morel and Huyen (Normal), and Liu and Zenner.

Much of this data for the steel materials are from experimental campaigns conducted in the 1970 and 1980 by German researchers. The cyclic biaxial state is achieved

TABLE 2 Fatigue data taken from the literature

\begin{tabular}{llll} 
Material & Reference & Biaxiality Ratio & Load Ratio \\
\hline XC48 & Simburger $^{1}$ & $2 / 1$ & 0 \\
St35 & Issler $^{5}$ & $1 / 0.55$ & 0.05 \\
25CrMo4 & Mielke $^{2}$ & 0.5 & 0.1 \\
34Cr4 & ${\text { Hendenreich et } \mathrm{al}^{6}}^{6}$ & 1 & 0.1 \\
ER7 & Koutiri et al $^{66}$ & 1 & 0.1 \\
2024-O & Bellett et al $^{58}$ & 0.4 & 0.1 \\
CrMo steel & Gaur et al $^{53}$ & 1 & 0.25 \\
\hline
\end{tabular}
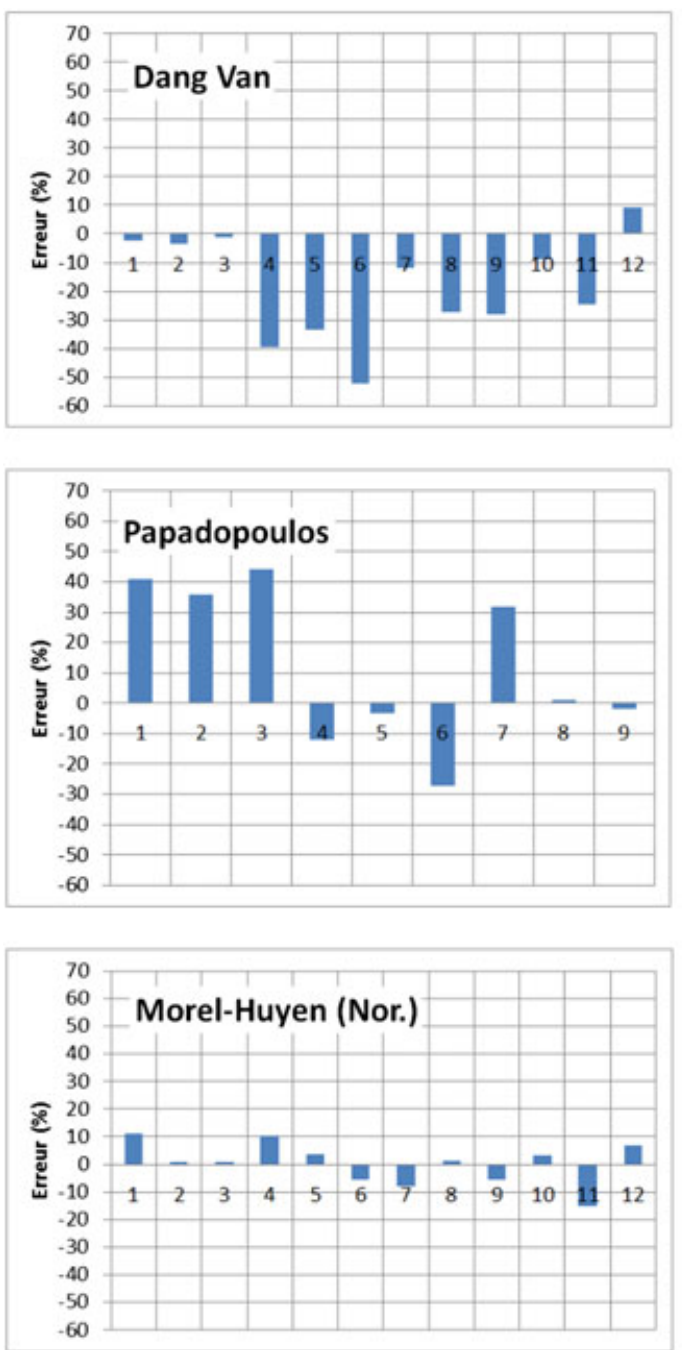

using combined internal pressure and tension. For the ER7 steel, the biaxial tensile stress is achieved via asymmetrical bending, ${ }^{66,67}$ and for the 2024-O aluminium, the biaxial stress state is obtained using specially shape specimen for uniaxial loading.

Five criteria have been investigated in terms of the way in which they treat the mean stress effect:

- The Dang Van, the Papadopoulos, and the Morel and Huyen (Hyd.) criteria use the hydrostatic stress to predict the mean stress effect, while the Morel and Huyen (Normal) and Liu and Zenner criteria are based on the integration of the normal stresses on material planes.

- Also, the Dang Van and Papadopoulos criteria do not have a specific model parameter dedicated to the mean stress effect. In these criteria, the coefficient $\alpha$ is defined in terms of the maximum hydrostatic stress. This same coefficient also takes into account the effect of a biaxial stress state. The 3 other criteria include a coefficient directly linked to the mean stress.
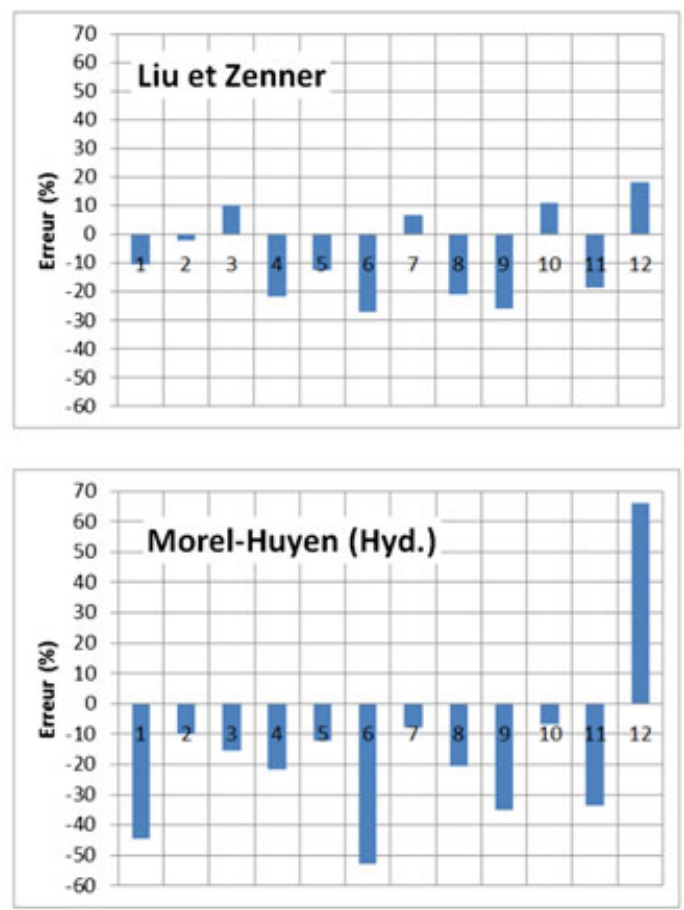

1. $34 \mathrm{Cr} 4$ [6]

2. St $35\left(\Sigma_{x x, \max }=153 \mathrm{MPa}\right)[5]$

3. St $35\left(\Sigma_{\text {xxmoy }}=169 \mathrm{MPa}\right)[5]$

4. XC $48\left(\Sigma_{x x, \text { moy }}=339 \mathrm{MPa}\right)[1]$

5. XC $48\left(\Sigma_{x a, \text { moy }}=367 \mathrm{MPa}\right)[1]$ 6. ER7 [60]

7. $25 \mathrm{CrMo} 4(\mathrm{k}=0.5)$ [2]

8. $25 \mathrm{CrMo} 4(\mathrm{k}=1)[2]$

9. CrMo Steel $(k=1)$ [53]

9. $2024-0 \quad\left(\Sigma_{x x \text { max }}=0 \mathrm{MPa}\right)$ [52]

10. $2024-0 \quad\left(\Sigma_{x x \text { may }}=105 \mathrm{MPa}\right)$ [52]

11. $2024-0 \quad\left(\Sigma_{x x \text { may }}=200 \mathrm{MPa}\right)[52]$

FIGURE 9 Predictions errors from the different criteria investigated for the 11 data sets taken from the literature for biaxial stress states [Colour figure can be viewed at wileyonlinelibrary.com] 
Figure 9 shows the prediction errors for each model for the different data sets taken from the literature (presented on Table 2) for biaxial stress states. Note that for several materials, different mean stresses and biaxiality ratios could be tested. For a fixed average stress and a given biaxiality ratio, the percentage error is calculated via the following expression:

$$
\operatorname{error}(\%)=\left(\frac{\Sigma_{x x, a}^{\text {predicted }}-\Sigma_{x x, a}^{\text {experimental }}}{\Sigma_{x x, a}^{\text {experimental }}}\right) \times 100 .
$$

The results of the comparison between the criteria predictions and the experimentally determined fatigue strengths for different data taken from the literature can be summarised as

- The Dang Van and Papadopoulos criteria have difficulty predicting the fatigue behaviour under biaxial tensile stress states. The predictions are correct (less than 5\% error) for only a few data sets, and no real trend is observed. In general, the Dang Van criterion underestimates the fatigue strength. However, the Papadopoulos criterion underestimates the fatigue strength for some materials (XC48, 2024-O, and ER7) and overestimates it for the other cases.

- The Liu and Zenner criterion gives good prediction errors, especially for the materials: $34 \mathrm{Cr} 4,25 \mathrm{CrMo} 4$, and St35. For the materials XC48 and steel ER7, the criterion underestimates the fatigue strength.

- The Morel and Huyen (Hyd.) criterion, which uses the hydrostatic stress, is conservative and underestimates the material fatigue strength. However, when the same criterion is used with the normal stress, with a maximum error of approximately $15 \%$ for the $2024-\mathrm{O}$ material (data set 10), note however that all of the criteria have difficulty predicting this data.

As a general rule, it can clearly be seen that the criteria using the hydrostatic stress as the parameter to take into account the spherical part of the cyclic stress tensor, to predict the effect of the biaxiality and the mean stress, are not suitable to predict the fatigue behaviour for biaxial stress states. However, the criteria using the normal stress, such as the Liu and Zenner or the Morel and Huyen (Normal) criteria, better reflect the material behaviour in fatigue under biaxial tensile loads. In particular, the Morel and Huyen (Normal) criterion appears most suitable for this loading mode. Furthermore, the hydrostatic stress overestimates the damage created by the loading condition.

\section{5 | DISCUSSION}

The aim of the first part of this paper, which presents a comparison between different HCF criteria, was to identify the loading conditions for which the predictions from the different criteria are not in agreement. The biaxial stress state, with or without mean stress, was clearly identified as being problematic. The aim of the second part of the paper was to clarify which criteria give the best predictions for these loading conditions and to identify why.

\section{Concerning the mean stress effect}

It is well accepted in the scientific literature that fatigue crack initiation in homogeneous metallic materials is caused by microplasticity at the scale of individual grains. However, there is no such consensus concerning the effect of the mean stress on crack initiation, other than the argument that it has an effect on the opening stress and propagation of microstructurally short cracks and that it facilitates the crossing of microstructural barriers.

Most of the proposed criteria take into account the effect of the mean stress in an empirical or phenomenological manner $28,31,34,39$ and often assume that the effect is linear. Typically, a model parameter is used to control the effect of the mechanical quantity chosen to represent the spherical part of the cyclic stress tensor. This mechanical quantity is generally either the hydrostatic stress, the normal stress on a material plane (or a critical plane), or a spatial average of all possible material planes.

The hydrostatic stress is related to the first invariant of the stress tensor and has the advantage of being very simple to calculate. However, there is more physical justification for the use of the normal stress on a material plane, but its calculation is sometimes time-consuming especially when using integral methods.

Nevertheless, regardless of which mechanical quantity is used to take into account the effect of a positive mean stress, it is shown above that the predictions are very different depending on the criterion used, at least for the example of the $34 \mathrm{CrMo} 4$ alloy steel. It should be noted however that all models predict a damaging effect of a positive uniaxial mean stress, which is more or less pronounced, and that the difference between the criteria becomes greater for the highest load ratios. Hence, it can be concluded that for the case of high mean stress, the criteria require other ingredients or more physically based parameters, to take into account the evolution of the fatigue damage and strain hardening, for example.

For instance, Ince and Glink ${ }^{68}$ have proposed a modification to the Morrow and the Smith, Watson, and Topper mean stress correction models to better account for the mean stress effect. In this work, the predictions of the proposed modifications are compared to those of the original Morrow and the Smith, Watson, and Topper models. Four sets of experimental fatigue data (Incoloy 901 superalloy, ASTM A723 steel, 7075-T561 aluminium alloy, and 1045 HRC 55 steel) were selected to investigate the predictive capabilities of the proposed model. It was found to 
provide good correlation with experimental data, except for compressive loading conditions.

Another way to deal with this issue is to turn to the family of models based on coupled plasticity and damage. Monchiet et al ${ }^{69,70}$ proposed an approach based on coupled plasticity and damage, which takes into account the role of the mean stress by considering the damage that appears in persistent slip bands (at the origin of crack initiation). The authors take into account this porosity by using the Gurson criteria and the concept of elastic shakedown. They demonstrated that evolution depends on both the level of the mean stress and the amplitude of the applied loading. The mechanical parameter used by the authors to reflect the effect of the mean stress is the hydrostatic stress. More recently, a coupled plasticity/damage approach has been proposed by Zghal ${ }^{71}$ to take into account the competition between the beneficial effect of strain hardening and the detrimental effect of damage.

\section{Concerning the effect of a biaxial stress state}

It is shown above that the effect of stress biaxiality in HCF depends on the loading mode under consideration. The predictions from the chosen fatigue models make it clear that for loading modes such as in-phase tension-torsion, the criteria are in good agreement with results that are practically the same. However, for other proportional loads, and in the particular the case of biaxial tension, the results are very different. Certain criteria predict that a biaxial stress state is not damaging in fatigue, while others predict that it is. Furthermore, no definitive experimental trend can be found in the literature.

When an equibiaxial tensile loading condition is combined with mean stresses, very significant differences are observed between the predictions from the different criteria. It is shown above that better predictions are obtained when using the normal stress with a coefficient dedicated to the mean stress effect to take into account the biaxiality effect (in biaxial tension).

\section{6 | CONCLUSION}

The aim of this work was to better understand the effect of mean stress and stress biaxiality in HCF and to examine the way different criteria take these effects into account. It can be concluded that

- Even for simple uniaxial tensile loads, the HCF multiaxial criteria investigated result in very different predictions for the effect of the mean stress.

- For the case of synchronous in-phase tension-torsion loads, with no mean stress, all of the investigated criteria converge to very similar predictions.

- For the case of biaxial tensile loads, no general trends can be observed in the predictions of the investigated criteria. For an equibiaxial state, some criteria predict a detrimental effect, others predict a beneficial effect.

- For equibiaxial stress states including mean stresses, the different criteria result in very different predictions.

- Via an analysis of experimental data taken from the literature, it is shown that most appropriate mechanical parameter to take into account the effect of a biaxial stress state and the mean stress effect is a weighted average of the normal stress on all possible material planes, such as that used by the Morel and Huyen (Normal) criterion.

It should be noted that the above conclusions are based on data taken from the literature for steel and aluminium materials, which can be qualified as being relatively defect free. Caution should be exercised when translating these conclusions to materials in which the fatigue behaviour is controlled by the presence of defects, for example, cast materials.

\section{ACKNOWLEDGEMENTS}

This work was undertaken in partnership with PSA Peugeot Citroën and was financially supported by the French region, Pays de la Loire.

\section{ORCID}

Imade Koutiri $(1$ http://orcid.org/0000-0002-0315-5863

\section{REFERENCES}

1. Simburger A. Festigkeitsverhalten zäher werkstoffe bei einer mehrachsiger phasenverschobenen schwingbeanspruchung mit körperfesten und veranderlichen hauptspannungsrichtungen. Technical Report Nr.FB-121, 247 p., Laboratorium fur Betriebsfestigkeit (L.B.F.), Darmstadt, Germany; 1975.

2. Mielke S. Festigkeitsverhalten metallischer werkstoffe unter zweiachsiger schwingender beanspruchung mit verschiedenen spannungszeitverlufen. PhD thesis: RWTH Aachen, 89 p; 1980.

3. Froustey C, Laserre S. Fatigue des aciers sous sollicitations combinées: Application à l'acier 30ncd16. Technical report, Ensam Rapport DRET-LAMEF-ENSAM, contrat 87 /115; 1988.

4. Dubar L. Fatigue multiaxiale des aciers. Passage de l'endurance à l'endurance illimitée. Pris en compte des accidents gomtriques. PhD thesis: Arts et Métiers ParisTech, Centre de Bordeaux; 1992.

5. Issler I. Festigkeitsverhalten metallischer werkstoffe bei mehrachsiger phasenverschobener beanspruchung. PhD thesis: University of Stuttgart, Germany; 1973.

6. Hendenreich R, Richter I, Zenner H. Schubspannungs intensitäts-hypothese-weitere experimentelle und theorestiche untersuchungen. Konstruktion. 1984;36:99-104.

7. Baier FJ. Zeit und dauerfestigkeit bei uberlagerter statischer und schwingender zugdruck und torsionsbeanspruchung. $P h D$ thesis: University of Stuttgart, Germany; 1970.

8. Bellows RS, Muju S, Nicholas T. Validation of the step test method for generating Haigh diagrams for Ti-6Al-4V. Int J Plast. 1999;21:687-697. 
9. Kluger K, Lagoda T. Application of the Dang Van criterion for life determination under uniaxial random tension compression with different mean values. Fatigue Fract Eng Mater Struct. 2004;27:505-512.

10. Karadag M, Stephens RI. The influence of high ratio on unnotched fatigue behavior of 1045 steel with three different heat treatments. Int J Fatigue. 2003;25:191-200.

11. Goodman J. Mechanics Applied to Engineering: London, UK: Longmans, Green and Co.; 1899.

12. Gerber WZ. Bestimmung der zulssigen spannungen in eisen-constructionen. Z Bayer Archit Ing Ver. 1874;6(6):101-110.

13. Davoli P, Bernasconi A, Filippini M, Foletti S, Papadopoulos IV. Independence of the torsional fatigue limit upon a mean shear stress. Int J Fatigue. 2003;25(6):471-480.

14. Morishita T, Itoh T. Evaluation of multiaxial low cycle fatigue life for type 3161 stainless steel notched specimen under non-proportional loading. Theor Appl Fract Mech. 2016;84:98-105.

15. Gates N, Fatemi A. Multiaxial variable amplitude fatigue life analysis including notch effects. Int J Fatigue. 2016;91:337-351.

16. Pook LP. A 50-year retrospective review of three-dimensional effects at cracks and sharp notches. Fatigue Fract Eng Mater Struct. 2013;36(8):699-723.

17. You BR, Lee SB. A critical review on multiaxial fatigue assessments of metals. Int J Fatigue. 1996;18(4):235-244.

18. Wang YY, Yao WX. Evaluation and comparison of several multiaxial fatigue criteria. Int J Fatigue. 2004;26(1):17-25.

19. Papuga J. A survey on evaluating the fatigue limit under multiaxial loading. Int J Fatigue. 2011;33(2):153-165.

20. Papadopoulos IV, Davoli P, Gorla C, Filippini M, Bernasconi A. A comparative study of multiaxial high-cycle fatigue criteria for metals. Int J Fatigue. 1997;19(3):219-235.

21. Matake T. An explanation on fatigue limit under combined stress. Bull JSME. 1977;141:257-263.

22. McDiarmid. A shear stress based critical-plane criterion of multiaxial fatigue failure for design and life prediction. Fatigue Fract Eng Mater Struct. 1994;17:1475-1484.

23. Susmel L, Tovo R, Lazzarin P. The mean stress effect on the high-cycle fatigue strength from a multiaxial fatigue point of view. Int J Fatigue. 2005;27:928-943.

24. Crossland B. Effect of Large Hydrostatic Pressures on the Torsional Fatigue Strength of an Alloy Steel. London: Institution of Mechanical Engineers, International Conference on Fatigue on Metals; 1956. 138-149.

25. Sines G. Metal Fatigue. Behavior of Metals Under Complex Static and Alternating Stresses. New York: Mac Graw Hill; 1959. 145-169.

26. Morel F. A critical plane approach for life prediction of high cycle fatigue under multiaxial variable amplitude loading. Int $J$ Fatigue. 2000;22(2):101-119.

27. Morel F, Huyen N. Plasticity and damage heterogeneity in fatigue. Theor Appl Fract Mech. 2008;49(1):98-127.

28. Dang Van K. Sur la résistance à la fatigue des métaux. Sciences et Techniques de l'armement, mémorial de l'artillerie française, 3eme facicule. 1973.

29. Papadopoulos IV. High-Cycle Metal Fatigue: From Theory to Applications, chapter 3 - Multiaxial fatigue limit criterion of metals: A mesoscopic scale approach. Cism International Centre for Mechanical Sciences Courses and Lectures: Springer: New York, USA; 1999.

30. Findley WN. A theory for the effect of mean stress on fatigue of metals under combined torsion and axial load or bending. $J$ Eng Ind (Transactions of ASME). 1959;4:113-125.
31. Liu J, Zenner H. Berechnung der dauerschwingfestigkeit bei mehrachsiger beanspruchung. Mat-Wiss. u. Werkstofftech. 1993;24:240-249.

32. Dang Van K. High-Cycle Metal Fatigue: From Theory to Applications, chapter 2 - Introduction to fatigue analysis in mechanical design by the multiscale approach. Cism International Centre for Mechanical Sciences Courses and Lectures: Springer: New York, USA; 1999.

33. Charkaluk E, Constantinescu A, Maitournam H, Dang Van K. Revisiting the Dang Van criterion. Procedia Eng. 2009;1(1):143-146.

34. Papadopoulos YV. Fatigue limit of metals under multiaxial stress conditions: the microscopic approach, technical note ni.93.101. Technical report, Commision of the European Communities Joint Research Center, ISEI/IE 2495/93; 1993.

35. Liu J, Zenner H. Fatigue limit of ductile metals under multiaxial loading. In: de Freitas M, Carpinteri A, Spagnoli A, eds. Biaxial/Multiaxial Fatigue and Fracture 6th International Conference on Biaxial/Multiaxial Fatigue and Fracture, European Structural Integrity Society, vol. 31: Elsevier: Oxford, UK; 2003:147-164.

36. Novoshilov VV. Theory of Elasticity (Rev. and edited by I.Meroz, Translated by J.J. Sherrkon. Jerusalem: Israel Program for Scientific Translation; 1961.

37. Grubisic V, Simbürger A. Fatigue under combined out-of-phase multiaxial stresses. Fatigue Testing and Design: papers presented at the international conference 5-9th April 1976 at the City University. London, England: Society of Environmental Engineers; 1976:27.1-27.8.

38. Papuga J, Ruzicka M. Two new multiaxial criteria for high cycle fatigue computation. Int J Fatigue. 2008;30:58-66.

39. Huyen Nguyen Thi Thu. Effet des hétérogneités microstructurales sur le comportement en fatigue multiaxiale à grand nombre de cycles. PhD thesis: Arts et Métiers ParisTech, Centre d'Angers, LPMI; 2008.

40. Weibull W. A statistical theory of the strength of materials. Roy Swed Inst Eng Res, Report. 1939;1-51.

41. Macha E, Sonsino C. Energy criteria of multiaxial fatigue failure. Fat Fract Eng Mater Struct. 1999;22:1053-1070.

42. Berto F, Campagnolo A, Lazzarin P. Fatigue strength of severely notched specimens made of Ti-6Al-4V. Fatigue Fract Eng Mater Struct. 2015;38:503-517.

43. Lazzarin P, Berto F, Zappalorto M. Rapid calculations of notch stress intensity factors based on averaged strain energy density from coarse meshes: theoretical bases and applications. Int $J$ Fatigue. 2010;32:1559-1567.

44. Froustey C, Laserre S, Dubar L. Validité des critères de fatigue multiaxiale à l'endurance en flexion-torsion MAT-TEC 92 Grenoble; 1992.

45. Palin-Luc T. Fatigue multiaxiale d'une fonte GS sous sollicitations combinées d'amplitude variable. PhD thesis: ENSAM CER Bordeaux; 1996.

46. Banvillet A. Prévision de la durée de vie en fatigue multiaxiale sous spectre de chargement réel : vers des essais accélérés. PhD thesis: ENSAM CER Bordeaux; 2001.

47. Tsybanev GV. An energy approach to fatigue tests and crack initiation stage determination. Translated from Problemy Prochnosti. 1994;2:19-27.

48. De Leiris H. Triaxialité des contraintes et critére de non-fragilité. Bulletin de l'Association Technique Maritime et Aéronautique. 1969:481-91.

49. Morel F, Palin luc T, Froustey C. Comparative study and link between mesoscopic and energetic approaches in high cycle multiaxial fatigue. Int J Fatigue. 2001;23:317-327. 
50. Marin J. Interpretation of fatigue strengths for combined stresses. In: Proceedings of the International Conference on Fatigue of Metals, Institution of Mechanical Engineers; London; 1956; 184-194.

51. Benabes J. Approche énergetique non locale du calcul de durée de vie de structures en fatigue multiaxiale sous chargements d'amplitude variable. Applicationá une roue de train ferroviaire. PhD thesis: ENSAM centre de Bordeaux, Fance; 2006.

52. Saintier N, Palin-Luc T, Benabes J, Cocheteux F. Non-local energy based fatigue life calculation method under multiaxial variable amplitude loadings. Int J Fatigue. 2013;54:68-83.

53. Gaur V, Doquet V, Persent E, Roguet E. Effect of biaxial cyclic tension on the fatigue life and damage mechanisms of Cr-Mo steel. Int J Fatigue. 2016;87:124-131.

54. Bonnand V, Chaboche L, Gomez P, Kanout P, Pacou D. Investigation of multiaxial fatigue in the context of turboengine disc applications. Int J Fatigue. 2011;33(8):1006-1016. Multiaxial Fatigue Models.

55. Joshi SR, Shewchuk J. Fatigue-crack propagation in a biaxial-stress field. Exp Mech. 1970;10(12):529-533.

56. Vansovich KA, Yadrov VI, Beseliya DC. The effect of stress state characteristics on the surface fatigue cracks growth rate taking into account plastic deformations. Procedia Eng. 2015;113:244-253.

57. Claudio RA, Reis L, Freitas M. Biaxial high-cycle fatigue life assessment of ductile aluminium cruciform specimens. Theor Appl Fract Mec. 2014;73:82-90. Special Issue on Current models in multiaxial fatigue and fracture - in memory of Professor Ewald Macha.

58. Bellett D, Morel F, Morel A, Lebrun JL. A biaxial fatigue specimen for uniaxial loading. Strain. 2011;47(3):227-240.

59. Doquet V, De Greef V. Dwell-fatigue of a titanium alloy at room temperature under uniaxial or biaxial tension. Int $J$ Fatigue. 2012;38:118-129.

60. Kane A, Doquet V. Surface crack and cracks networks in biaxial fatigue. Eng Fract Mech. 2006;73(2):233-251. Advanced Fracture Mechanincs for Life Safety Assessments.

61. Lee EU, Taylor RE. Fatigue behavior of aluminum alloys under biaxial loading. Eng Fract Mech. 2011;78(8):1555-1564.
62. Leevers PS, Radon JC, Culver LE. Crack growth in plastic panels under biaxial stress. Polymer. 1976;17(7):627-632.

63. Kitagawa H, Yuuki R. Analysis of branched cracks under biaxial stress. In: Taplin DMR, ed. Analysis and Mechanics. Pergamon; 1978:201-211. ISBN 978-0-08-022142-7.

64. Misak HE, Perel VY, Sabelkin V, Mall S. Biaxial tension-tension fatigue crack growth behavior of 2024-T3 under ambient air and salt water environments. Eng Fract Mech. 2014;118:83-97.

65. Poncelet M, Barbier G, Raka B, Vincent L, Desmorat R. Etude de l'endommagement dun acier inoxydable austénitique par fatigue multiaxiale grand nombre de cycles. Paris; 2009.

66. Koutiri I, Bellett D, Morel F, Augustins L, Adrien J. High cycle fatigue damage mechanisms in cast aluminium subject to complex loads. Int J Fatigue. 2013;47:44-57.

67. Koutiri I. Effet des Fortes Contraintes Hydrostatiques sur la Tenue en Fatigue des Materiaux metalliques. PhD thesis: ENSAM CER Angers, France; 2011.

68. Ince A, Glinka G. A modification of morrow and smith watson topper mean stress correction models. Fatigue Fract Eng Mater Struct. 2011;34:854-867.

69. Monchiet V, Charkaluk E, Kondo D. Plasticity-damage based micromechanical modelling in high cycle fatigue. $C R$ Méc. 2006;334(2):129-136.

70. Monchiet V, Charkaluk E, Kondo D. A micromechanical explanation of the mean stress effect in high cycle fatigue. Mech Res Commun. 2008;35(6):383-391.

71. Zghal J. High cycle fatigue behavior of a HC360LA high-strength low-alloy steel: Damage, plasticity and associated dissipative phenomena. PhD thesis.

How to cite this article: Koutiri I, Bellett D, Morel F. The effect of mean stress and stress biaxiality in high-cycle fatigue. Fatigue Fract Engng Mater Struct. 20171-16. https://doi.org/10.1111/ffe.12699 